\title{
PROPORCIONALIDADE "ECO-LÓGICA": um princípio jurídico emergente para a natureza?
}

\author{
Professor de Direito Público, Diretor do Centro de Pesquisa em Direito Ambiental Europeu \\ da Universidade de Bremen. Tradução: Beatriz Souza Costa: Mestre e Doutora em Direito \\ Constitucional pela UFMG. Professora no Curso de Mestrado em Direito Ambiental e Desen- \\ volvimento Sustentável, na disciplina Direito Constitucional Ambiental na Escola Superior \\ Dom Helder Câmara- ESDHC, Pró-Reitora de Pesquisa da ESDHC. Tasso Alexandre Richetti \\ Pires Cipriano: Bacharel em Direito pela Faculdade de Direito da Universidade de São \\ Paulo - FDUSP. Doutorando em Direito Ambiental pela FDUSP e pela Universität Bremen \\ Fachbereich Rechtswissenschaft, Alemanha. Pesquisador (wissenschaftlicher Mitarbeiter) da \\ Forschungsstelle für Europäisches Umweltrecht FEU da Universität Bremen. \\ gwinter@uni-bremen.de
}

Gerd Winter

\section{RESUMO}

A ecoproporcionalidade é proposta como uma possibilidade de estruturar o balanceamento de interesses de exploração e proteção da natureza, restringindo, assim, a discricionariedade embutida em conceitos como direitos da natureza, contrato natural, sustentabilidade e análise custo-benefício. Ecoproporcionalidade é uma analogia ao já firmado Princípio da Proporcionalidade, aqui chamado de Socioproporcionalidade. Ambos os princípios têm um denominador comum na medida em que realizam uma checagem de poder - poder do Estado sobre a sociedade e da sociedade sobre a natureza, respectivamente. Assim como a socioproporcionalidade, a ecoproporcionalidade requer quatro testes, nomeadamente um objetivo justificável de ação, adequação, necessidade e sopesamento de meios. O artigo procura mostrar que a ecoproporcionalidade já se mostra presente tanto como uma norma social quanto como uma norma jurídica. Há razão para sugerir que ela deveria entrar em mais esferas da prática social e da ordem jurídica, ao mesmo tempo tomando uma forma mais diferenciada e ambiciosa.

Palavras-chave: Direito Ambiental. Princípios de Direito Ambiental. Ecoproporcionalidade. Socioproporcionalidade. Autorregulação. Direito Transnacional. 


\section{ECO-LOGICAL PROPORTIONALITY: AN EMERGING PRINCIPLE OF LAW FOR NATURE?}

\section{ABSTRACT}

Eco-proportionality is proposed as a possibility of how to structure the balancing of interests of exploitation and protection of nature, thus fettering the discretion built into concepts like nature rights, the contrat naturel, sustainability and cost-benefit analysis. Eco-proportionality is an analogy to the well-established public law principle of proportionality, here called socio-proportionality. Both principles have a common denominator in that they make a check on power, power of the state over society and of society over nature, respectively. Like in socio-proportionality, ecoproportionality requires four tests, namely a justifiable objective of action and the effectiveness, necessity and weighing of means. It has been shown that the principle is already present both as a social and legal norm. There is reason to suggest that it should enter into more spheres of societal practice and legal order, at the same time taking a more differentiated and ambitious shape.

Keywords: Environmental Law. Principles of Environmental Protection. Eco-proportionality. Socio-proportionality. Self-regulation. Transnational Law.

\section{INTRODUÇÃO}

As abordagens para dar à natureza um lugar mais importante nas leis que governam as sociedades humanas têm muitas vezes conferido a ela direitos subjetivos em relação aos seres humanos. Um exemplo notável é reconhecer à natureza legitimidade processual ${ }^{1}$; outro é o construto de um Contrato Natural complementar ao Contrato Social ${ }^{2}$.

A dificuldade dessas sugestões reside no fato de que, enquanto no mundo real ponderar direitos conflitantes e chegar a acordos é necessário, o conceito de direito subjetivo não fornece diretrizes sobre como fazer isso. Por outro lado, o desenvolvimento sustentável está muito em voga

${ }^{1}$ Cf. Christopher D. Stone, Should Trees Have Standing? Law, Morality, and the Environment, 3.ed., Oxford, Oxford University Press, 2010.

${ }^{2}$ M. Serre, Contrat Naturel, Paris, Flammarion, 1992. 
enquanto um princípio objetivo (isto é, não baseado em direitos) voltado a aumentar o peso da proteção à natureza. Contudo, referido princípio tem sido amplamente considerado ineficaz, haja vista permitir, ao menos da maneira como tem sido entendido, qualquer sopesamento de interesses econômicos, sociais e ambientais, na maioria das vezes em favorecimento dos interesses econômicos ${ }^{3}$.

Outro conceito objetivo é a análise de custos econômicos e benefícios ambientais de políticas ambientais ${ }^{4}$. Entretanto, na medida em que referido conceito insiste em usar denominadores comuns de análise, seu método de monetarização (quantificação) de valores qualitativos não vem sendo convincente. Por outro lado, se o conceito se contenta com um sopesamento unicamente qualitativo, revela-se, então, desprovido de critérios objetivos para se chegar a resultados aceitáveis.

Nesse contexto, recorre-se ao Princípio da Proporcionalidade como um princípio que promova o papel da natureza no Direito e forneça critérios adequados de sopesamento. Tal princípio emergiu como um meio sofisticado para a restrição do poder no âmbito da sociedade humana. Sugiro também usá-lo como meio de restrição de poder do homem sobre a natureza.

\section{DA PROPORCIONALIDADE "SÓCIO-LÓGICA" À "ECO-LÓGICA"}

\subsection{A tradição da proporcionalidade}

Proporcionalidade é um princípio amplamente aceito no Estado de Direito. Foi desenvolvido para estruturar as relações entre o poder governamental e os cidadãos e projetado para garantir que o Poder Público, ao intervir nos direitos dos cidadãos em busca do interesse público, o faça sob certas pré-condições, a saber:

- o objetivo perseguido pelo governo deve ser justificável (1);

- a medida adotada deve ser: adequada, isto é, capaz de servir ao interesse público (2); necessária, isto é, insubstituível por qualquer medida

\footnotetext{
${ }^{3}$ Para maiores considerações sobre o Princípio do Desenvolvimento Sustentável, incluindo uma leitura da sustentabilidade "forte", cf. Paulo Affonso Leme Machado, Direito ambiental brasileiro, 21. ed., São Paulo, Malheiros, 2013, p. 73-90.

${ }^{4}$ Para um panorama sobre o estado da arte a respeito, cf. B.C.Field and K.C. Field, Environmental Economics, 5.ed., Boston, McGraw-Hill, 2009, p. 44 e seguintes, p. 118 e seguintes, p. 137 e seguintes.
} 
alternativa e igualmente efetiva, mas menos intrusiva a direitos individuais (3); e proporcional em sentido estrito (sopesada), isto é, não excessivamente intrusiva a direitos individuais tendo em vista a importância do interesse público (4).

O Princípio da Proporcionalidade pode ser representado como indicado na figura 1 . As flechas indicam que a medida adotada interferirá de um modo ou de outro em direitos individuais para o alcance de um objetivo. A seta pontilhada representa uma medida alternativa $B$ que, por ser mais intrusiva que a alternativa $\mathrm{A}$, é rejeitada.

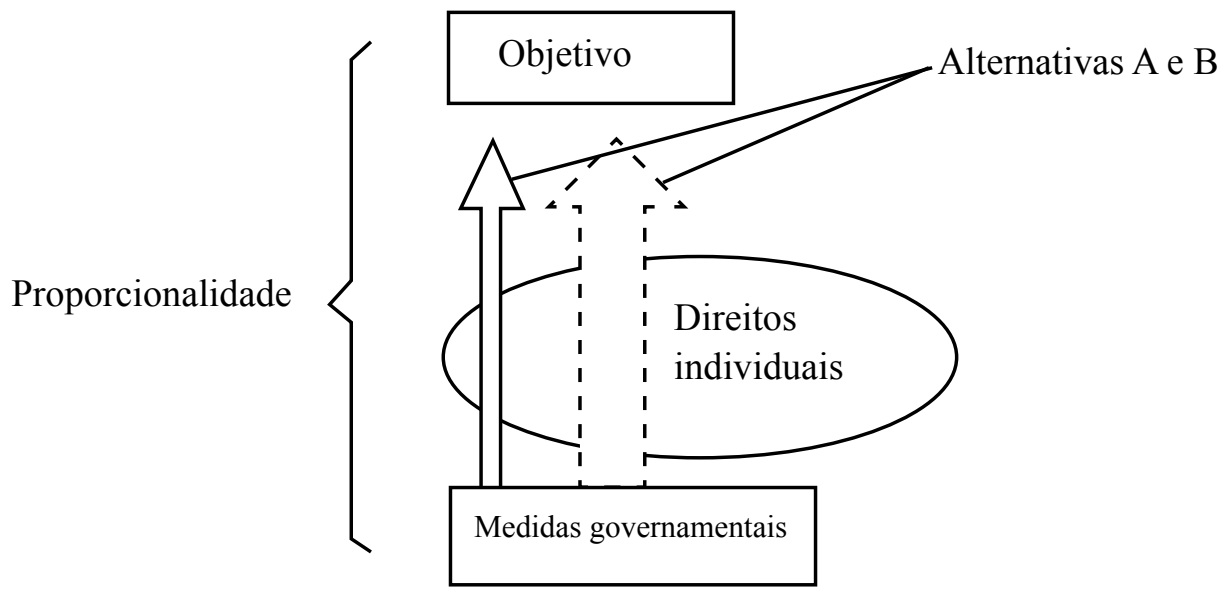

Figura 1: O tradicional Princípio da Proporcionalidade

Proporcionalidade (Verhältnismäßigkeit, em alemão) tem origens jurídicas e culturais variadas, sendo a alemã possivelmente a mais influente.

$\mathrm{Na}$ Alemanha, o princípio originou-se no direito de polícia do século XIX, quando os tribunais desenvolveram a doutrina segundo a qual o exercício do poder de polícia, a fim de garantir a ordem pública, não deve interferir em direitos individuais para além do necessário a assegurá$1 \mathrm{a}^{5}$. Isso implicou dois testes: primeiro, a medida menos invasiva deve ser escolhida; segundo, ela não pode ser desproporcional ao problema a ser solucionado. Gradualmente o princípio tornou-se mais diferenciado e foi desenvolvido como uma verificação geral de ação administrativa discri-

${ }^{5}$ V. Götz, Allgemeines Polizei- und Ordnungsrecht, 11.ed., Göttingen, Vandenhoeck\& Ruprecht, 1993, p.130 e seguintes. 
cionária e até mesmo como um princípio constitucional de controle do Poder Legislativo quando uma lei intervém em direitos básicos ${ }^{6}$. No Direito Administrativo francês, observa-se um desenvolvimento parecido, embora mais ligado ao Direito Administrativo setorial?

A instituição da proporcionalidade nos sistemas jurídicos alemão e francês facilitou o seu caminho para o nível europeu. Neste, o Princípio da Proporcionalidade poderia também ser casado com o Princípio da Razoabilidade, o qual deriva do direito consuetudinário inglês enquanto padrão de verificação da discricionariedade administrativa, apesar de mais processual e menos sistemático que o teste da proporcionalidade ${ }^{8}$. O Tribunal de Justiça da União Europeia (TJUE) adotou o Princípio da Proporcionalidade em sua jurisprudência em matéria de direitos fundamentais europeus como meio de restringir intrusões por parte de autoridades europeias 9 . Num segundo momento, o princípio foi aplicado para restringir, em sede de controle europeu, intrusões sobre liberdades básicas europeias também por parte dos Estados-Membros ${ }^{10}$.

Assim, a proporcionalidade tornou-se um princípio abrangente de domesticação dos poderes governamentais quando interferem em direitos individuais ou no domínio de competência de esferas de governança de nível inferior.

\subsection{Analogia sugerida}

Minha sugestão é que o Princípio da Proporcionalidade não devesse ser aplicado somente para atividades governamentais que interfiram nos direitos dos cidadãos, mas também para aquelas atividades dos cida-

\footnotetext{
${ }^{6}$ P. Lerche, Übermaß und Verfassungsrecht. Zur Bindung des Gesetzgebers an die Grundsätze der Verhältnismäßigkeit und Erforderlichkeit, Köln, C. Heymanns Verlag, 1961, p. 29 e seguintes.

${ }^{7} \mathrm{O}$ direito de polícia (Polizeirecht) e o direito da expropriação (Enteignungsrecht, expropriation law) serviram como campo de aprendizado, respectivamente, do teste da menor intrusão (necessidade) e do sopesamento de interesses públicos e privados, este último denominado bilan coût-avantages. Cf. G. Dupuis ; M.-J. Guédon ; P. Crétien, Droit Administratif, 12.ed., Paris, Dalloz, 2011, p. 841.

${ }^{8}$ H. W. R. Wade, Administrative Law, 5.ed., Oxford, Clarendon Press, 1982, capítulo 12. Há quem sugira a adoção da proporcionalidade como um princípio da common law, cf. C. Harlow; R. Rawlings, Law and Administration, Cambridge, Cambridge University Press, 1997, reimpressão de 2006, p. 118.

${ }^{9}$ Decisão da TJUE de 17.12.1970, Caso 11/70 (Internationale Handelsgesellschaft) parágrafos $12 \mathrm{e}$ 14.

${ }^{10}$ Apesar de desenvolvido para situações envolvendo intrusões em direitos individuais básicos, o Princípio da Proporcionalidade foi estendido para checar invasões de competência por parte de esferas superiores de governo (instituições europeias) sobre esferas inferiores (Estados-Membros). Vide, ilustrativamente, o Art. 5 (4) do Tratado da União Europeia (TUE), no qual o Princípio da Proporcionalidade funciona como um complemento do Princípio da Subsidiariedade.
} 
dãos que impactem a natureza.

Essa analogia é justificável porque as duas áreas de aplicação têm um denominador comum, ou seja, a limitação ao poder. No primeiro caso é o poder do Estado sobre a sociedade (ou do coletivo sobre o individual) que tem que ser limitado.

A proporcionalidade no segundo caso seria uma exigência de justificar o uso da natureza pela sociedade. "Sociedade" incluiria não apenas pessoas físicas e empresas, mas também entes governamentais, não como reguladores, mas como usuários diretos da natureza.

A fim de aclarar a terminologia, sugiro nomear os dois tipos de proporcionalidade: "sócio-lógica" e "eco-lógica". Enquanto a proporcionalidade sócio-lógica (ou, em síntese, socioproporcionalidade) deve proteger essencialmente os direitos básicos dos cidadãos frente às intrusões governamentais, a proporcionalidade eco-lógica (ou ecoproporcionalidade) deve proteger a natureza frente às intrusões da sociedade (incluindo o governo consumidor da natureza).

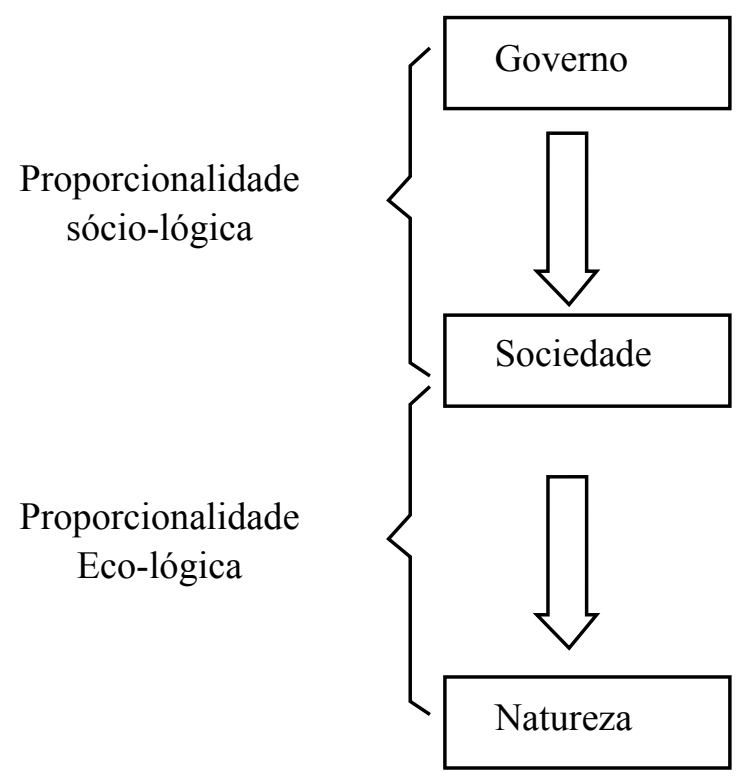

Figura 2: Duas versões da proporcionalidade 
A razão para essa nova forma de encarar o Princípio da Proporcionalidade é o aumento da escassez de recursos naturais disponíveis para a sociedade moderna, seja a biodiversidade, a água, o ar limpo ou um clima no qual seja possível viver.

O corolário disso é que os membros da sociedade não são considerados apenas titulares de direitos, mas também portadores de obrigações (embora isso não exclua ações baseadas em direitos contra aqueles que não cumprirem suas obrigações). O ponto crucial é que a sociedade humana está obrigada a justificar seus interesses frente à natureza. Esta não é mais o mero ambiente da humanidade a ser protegido mediante limites físicos às incursões humanas. Pelo contrário, é um recurso que deve ser preservado, a não ser que haja um bom motivo para consumi-lo.

\subsection{Projetando a proporcionalidade eco-lógica}

A ecoproporcionalidade implicaria o seguinte teste, composto por quatro etapas: se uma atividade interfere em recursos naturais, o ator deve perseguir um objetivo social justificável (1), a atividade deve ser prospectivamente adequada, isto é, capaz de servir ao objetivo (2), necessária, isto é, não substituível por qualquer medida alternativa menos intrusiva aos recursos naturais (3) e proporcional em sentido estrito (sopesada), ou seja, não excessivamente intrusiva aos recursos naturais em face da importância do objetivo social (4).

O princípio pode ser representado da seguinte forma:

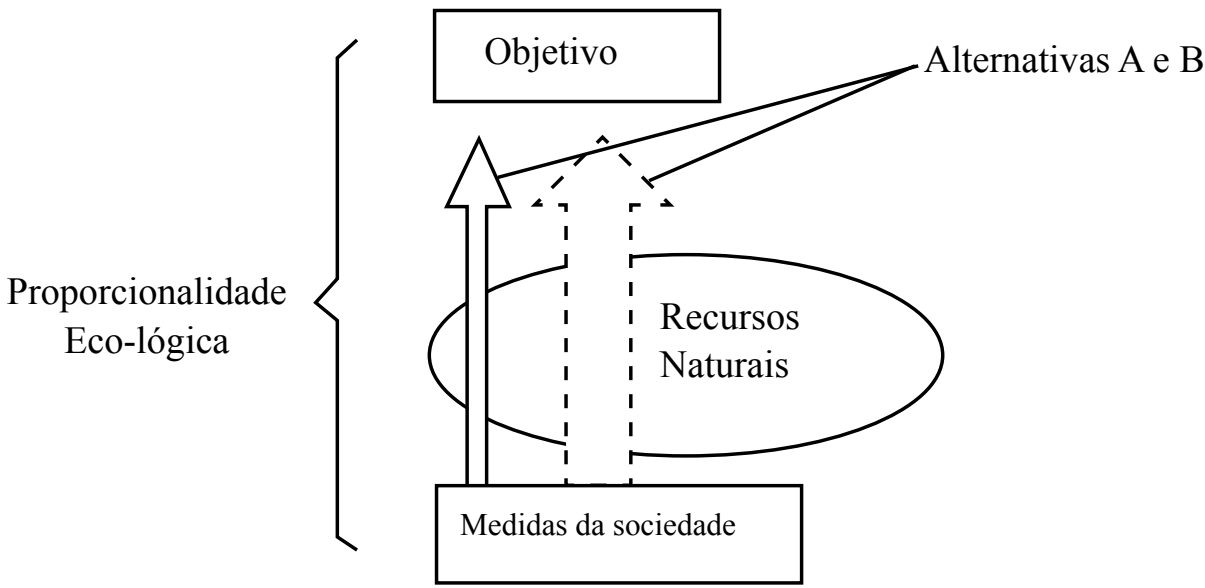

Figura 3: Ecoproporcionalidade 
De modo mais detalhado, uma versão ambiciosa desse teste exigiria os seguintes quatro requisitos:

(1) Enquanto no contexto da socioproporcionalidade se concebe aos indivíduos uma liberdade de perseguir seus objetivos, na ecoproporcionalidade a persecução dos objetivos pelos indivíduos sujeita-se a um dever de dar razões. Isso é um verdadeiro scandalon do conceito, mas é compreensível diante da crescente escassez de recursos naturais. Não é justificável, por exemplo, usar produtos agrícolas como biocombustível onde eles sejam necessários para o consumo humano ou mesmo capturar animais raros para tê-los como animais de estimação. Usos não justificáveis são também antijurídicos;

(2) Se um objetivo é justificável, os meios adotados devem ser aptos à sua consecução. Por exemplo, se uma represa para geração de energia hidrelétrica for construída, é necessário comprovar que o rio vá alimentar suficientemente aquele reservatório;

(3) O elemento praticamente mais importante da ecoproporcionalidade é o teste dos meios alternativos. A medida alternativa que causar os menores efeitos adversos aos recursos naturais deve ser preferida. Todavia, como nem todas as medidas alternativas atingirão o objetivo exatamente da mesma maneira, deve-se aceitar algum desvio quanto ao pleno alcance do objetivo;

(4) Assumindo que um objetivo é justificável e os meios para atingi-lo são adequados e também necessários, esses meios deveriam ser, contudo, rejeitados se os seus efeitos adversos à natureza forem excessivos quando sopesados com a importância do objetivo. Por exemplo, se, devido a fatores geográficos, a ampliação de uma rodovia somente puder ser realizada atravessando-se uma reserva natural, mas aumentaria a capacidade de transporte em apenas 5\%, o efeito adverso pode ser considerado excessivo em relação ao objetivo.

Com efeito, é demasiado ambicioso sugerir a introdução desse método para todas as áreas em que recursos naturais escassos sejam utilizados. No entanto, seria um grande passo à frente se pelo menos a consideração de alternativas se tornasse uma exigência geral, mesmo que o objetivo da atividade permanecesse completamente à discricionariedade do ator. $\mathrm{O}$ alcance concreto dos dois elementos mais importantes - objetivo justificável e teste das alternativas - serão a seguir explicados.

No que tange à exigência de um objetivo razoável, o alcance da justificativa possível varia desde o prazer pessoal e o lucro econômico até o 
valor de uso de um produto ou serviço e até mesmo um interesse público.

Em relação ao interesse público, deveria ser exigido, quando for inevitável, que bens de elevado valor ambiental sejam sacrificados em nome da consecução do objetivo, a exemplo da destruição de um habitat natural em prol da instalação de uma melhor infraestrutura de transporte.

Nesse aspecto, quanto mais sério o dano ou risco de dano, maior deve ser o peso do benefício caso o efeito ambiental adverso seja aceito. Como o objetivo é um guia apropriado para determinar o escopo das alternativas a serem consideradas, deve-se considerar que, quanto mais abrangente o objetivo for formulado, mais amplo se torna o alcance das alternativas. Por exemplo, se o objetivo definido for facilitar o transporte entre dois aglomerados, rodovias e ferrovias são duas opções a serem consideradas. Se, no entanto, o objetivo for definido de forma menos abrangente, como facilitar o transporte individual, somente diferentes tipos e linhas de estradas seriam incluídas.

Finalmente, se o objetivo for determinado especificamente para que uma rodovia de seis pistas seja construída em um corredor precisamente delimitado, então apenas poucas alternativas podem ser consideradas. Um arranjo apropriado seria que todas as decisões no primeiro e no segundo caso devessem ser tomadas em um nível administrativo superior e inferior, respectivamente, enquanto o terceiro caso não deveria ser aceito em absoluto, por não distinguir adequadamente entre objetivos e meios.

No que concerne o papel das alternativas, a escolha de opções pode ser deixada subjetivamente ao empreendedor ou pode seguir critérios objetivos. Por exemplo, a Diretiva 2011/92/UE relativa à avaliação de impacto ambiental de projetos confina o teste às "principais alternativas estudadas pelo empreendedor" ${ }^{11}$. Diversamente, a Diretiva 2001/42/CE sobre a avaliação de impacto ambiental de planos refere-se a "alternativas razoáveis" 12 . Esta linguagem é mais objetiva, vez que não adstrita à escolha subjetiva do empreendedor e, portanto, menos inclinada ao uso incorreto por ele.

Quanto ao escopo das alternativas a serem verificadas, como já mencionado, o objetivo (privado ou público) do uso da natureza deve servir como critério. Além disso, deve-se esclarecer se a compensação de

\footnotetext{
${ }^{11}$ Directiva 2011/92/UE do Parlamento Europeu e do Conselho relativa à avaliação dos efeitos de determinados projetos públicos e privados no ambiente, JO 2012 L 26/1, Anexo IV Seção 2.

${ }^{12}$ Directiva 2001/42/ do Parlamento Europeu e do Conselho de 27 de junho de 2001 relativa à avaliação dos efeitos de determinados planos e programas no ambiente, JO 2011 L 197/30, art. 5 (1).
} 
quaisquer danos causados por uma alternativa deve ser considerada redutora dos impactos negativos. E isso deve depender do tipo de recurso natural em jogo. Por exemplo, a remoção de recursos vivos deveria ser tratada diferentemente de poluição por químicos, haja vista o dano poder ser atenuado mais facilmente no primeiro caso que no segundo.

Um último problema está relacionado ao fato de as alternativas poderem ser diferentes quanto ao grau de alcance do objetivo e acarretarem diferentes custos financeiros. Por exemplo, é com certeza mais custoso construir um túnel em um determinado biótopo que uma travessia na superfície. Parece que tais questões - alcance dos objetivos e efeitos colaterais financeiros - devem ser resolvidas por meio de um sopesamento apropriado de interesses. Custos significativos e redução na consecução de objetivos podem ser razões para se aceitar uma alternativa que seja a segunda melhor ("second best") em termos ambientais.

\section{STATUS JURÍDICO}

Os exemplos mencionados já indicam que o Princípio da Proporcionalidade ecológica não é estranho à positivação. Entretanto, esse princípio deveria ser concebido primeiramente como uma norma social e não jurídica ${ }^{13}$. Mais que a socioproporcionalidade, a qual encoraja atos egoístas a não ser que o Estado trace limites, a ecoproporcionalidade é particularmente apropriada para emergir como norma social, haja vista ela visar a um autocomprometimento social de como a sociedade poderia utilizar os recursos naturais. Adicionalmente, a ecoproporcionalidade poderia ser enquadrada como uma exigência do direito positivo.

No item seguinte explora-se em que medida referido princípio já entrou no domínio das normas sociais e jurídicas.

\subsection{Uma norma social}

Nessa perspectiva, é possível perguntar se indivíduos, empresas e entes governamentais, ao fazerem uso de recursos naturais, refletem se

\footnotetext{
${ }^{13}$ A respeito da emergência e do papel das normas sociais enquanto distintas das normas jurídicas cf. o texto clássico de Max Weber, Rechtssoziologie, ed. J. Winckelmann, Neuwied, Luchterhand, 1960, p. 63 e seguintes. Para um rico estudo empírico sobre "folkways", vide W.G. Sumner, Folkways. A study of the sociological importance of usages, manners, customs, mores and morals, Boston, Ginn and Company, 1906.
} 
suas atividades prestam-se a um objetivo justificável, se o objetivo pode ser alcançado através de meios menos danosos e se os efeitos adversos remanescentes podem ser superados ante a importância do objetivo.

No mundo social, a ecoproporcionalidade difundiu-se efetiva e amplamente no âmbito do chamado consumo ambiental. Por exemplo, mais e mais consumidores comparam produtos e serviços não somente em termos de preço e funcionalidade, mas também em termos do impacto ambiental associado à produção, ao funcionamento e ao descarte deles. Não só as alternativas menos intrusivas são consideradas, como também os próprios objetivos do consumo são colocados em questão. $\mathrm{O}$ uso de bicicletas é um exemplo: em comparação com o carro ela é, em muitas situações, não apenas uma alternativa menos intrusiva (danosa), mas também apresenta um objetivo justificável melhor por ser mais rápida em centros urbanos e mais saudável para os ciclistas (quando existirem ciclovias).

No mundo econômico, códigos de conduta de empresas e redes empresariais às vezes contêm recomendações que refletem elementos de proporcionalidade ecológica. ${ }^{14}$ Enquanto muitas corporações internacionais se comprometem com objetivos vagos de comportamento econômico sustentáve ${ }^{15}$, outras se empenham em minimizar seus impactos ambientais e estão até mesmo preparadas para refletir os benefícios de seus produtos. Por exemplo, a companhia química suíça Novartis tem, entre os princípios de sua "Política de Cidadania Corporativa" concernente à saúde, segurança e performance ambiental, o seguinte ${ }^{16}$ :

Empenhamo-nos em fazer um uso eficiente dos recursos naturais e minimizar os impactos ambientais de nossas atividades e nossos produtos durante seu ciclo de vida. Nós avaliamos implicações à saúde, segurança e performance ambiental para assegurar que os benefícios de novos produtos, processos e tecnologias ultrapassem os riscos remanescentes.

\footnotetext{
${ }^{14} \mathrm{Há}$ longa data a autorregulação industrial introduz standards técnicos, tanto em nível nacional como regional (H. Schepel, The Constitution of Private Governance. Product Standards of Integrating Markets, Oxford, Hart Publishing, 2005, p. 101-176) e, mais recentemente, também em âmbito global (O. Dilling, 'Proactive Compliance? Repercussions of National Regulation in Standards of Transnational Business Networks' in O. Dilling, M. Herberg, G. Winter (eds.), Responsible Business. Self-Governance and Law in Transnational Economic Transactions, Oxford, Hart Publishing, 2008, p. 96-98. Tais standards (assim como esquemas mais ambiciosos, tais como a ISO 14000 sobre gestão ambiental) são elementos de um "direito ambiental empresarial" emergente. A ecoproporcionalidade iria para além dele, na medida em que exige colocar em questão os objetivos de produção e a busca por produtos alternativos.

${ }^{15}$ Cf., por exemplo, os sítios eletrônicos de corporações químicas multinacionais como a BASF e a Bayer.

${ }^{16}$ www.novartis.com/downloads/corporate-responsibility/ Acesso em: 26 ago. 2012. Infelizmente o princípio desapareceu do site. Talvez a empresa o tenha achado ambicioso demais.
} 
Essa cláusula de minimização pode ser vista como teste de alternativas, e a exigência de eficiência como forma de teste de adequação. Mais significativamente, a empresa está preparada para sopesar os benefícios dos produtos com os riscos ambientais remanescentes.

Um exemplo mais modesto pode ser encontrado nas orientações da OCDE sobre multinacionais. Apesar de derivarem de uma organização internacional composta por Estados, elas podem ser consideradas um padrão de autocompromisso compartilhado por indústrias progressivas. Entre as diretrizes, encontra-se a seguinte ${ }^{17}$ :

[As empresas devem]

6. Procurar continuamente melhorar a performance ambiental corporativa ao nível de empresa e, quando apropriado, da sua cadeia de suprimentos, encorajando atividades como:

a) adoção de tecnologias e procedimentos operacionais, em todas as partes da empresa, que reflitam os padrões da parte da empresa com os melhores padrões de performance ambiental;

b) desenvolvimento e fornecimento de produtos ou serviços que não tenham nenhum impacto ambiental indevido; sejam seguros em seu uso pretendido; reduzam a emissão de gases de efeito estufa; sejam eficientes no consumo de energia e recursos naturais; possam ser reutilizados, reciclados ou dispostos adequadamente.

As diretrizes reivindicam o emprego de tecnologias que não apresentem impactos ambientais indevidos, sejam seguras ao uso pretendido, reduzam as emissões de gases de efeito estufa e sejam eficientes no consumo, conforme os padrões da parte da empresa com os melhores padrões de performance ambiental como um todo. Embora isso não implique uma comparação com as melhores tecnologias globais, estimula-se a consideração de alternativas e uma orientação visando aos melhores padrões alcançados pela multinacional. Da mesma forma, ao escolher o tipo de produto ou serviço fornecido, a empresa deve respeitar critérios ambiciosos como "sem efeitos indevidos ao meio ambiente", uso seguro, redução de gases de efeito estufa, eficiência de energia e recursos, bem como o reúso, a reciclagem e a disposição adequada de resíduos.

Evidentemente, tais orientações são recomendações e autocompromissos, e não regras vinculantes, sendo formuladas em linguagem exor-

${ }^{17}$ OECD, OECD Guidelines for Multinational Enterprises, OECD Publishing, 2011. Disponível em: $<$ http://dx.doi.org/10.1787/9789264115415-en>, capítulo VI, número 6. Acesso em: 26 ago. 2012. 
tativa, não prescritiva. Elas são, contudo, exemplos de normas sociais. São consideradas auto-obrigatórias quanto mais concretas e apoiadas por uma infraestrutura organizacional, como agentes ambientais especializados, compromissos de comunicação (reporting commitments), planos de gerenciamento, mecanismos de auditoria interna etc. ${ }^{18}$

\subsection{A Norma Legal}

Conclui-se, então, ser o Princípio da Ecoproporcionalidade, de fato, uma norma social emergente. Ele é importante como uma fonte de autorregulação social, especialmente naquelas áreas em que o Direito ainda não tenha intervindo. A ecoproporcionalidade é, porém, também adequada enquanto teor de uma legislação estatal vinculante.

Evidentemente, também a legislação estatal pode formular regras básicas que a sociedade deve respeitar ao fazer o uso de recursos naturais. Na verdade, dada a urgência, nos dias de hoje, de passos mais ousados em direção à proteção ambiental, a ecoproporcionalidade pode servir como instrumento apropriado de guia para a sociedade no tocante a um maior respeito pela natureza.

É imperial demonstrar que o referido princípio não é completamente novo e já pode ser identificado em alguns textos legais. Os exemplos dados anteriormente, bem como alguns novos, podem mostrar que de fato esse é o caso. Tais exemplos referem-se, em nível regional e nacional, à União Europeia (UE) e à Alemanha, respectivamente, mas também englobam acordos internacionais.

Um exemplo bastante elaborado é um conjunto de critérios estabelecidos para a proteção da Rede Europeia de Áreas Protegidas, denominada Natura 2000. Se se percebe que um projeto causará efeitos adversos significativos sobre uma área pertencente à Natura 2000, ele pode ser excepcionalmente autorizado se não existirem soluções que não apresentem ou apresentem menos efeitos adversos e se, sopesando tais efeitos com um interesse público superior, o segundo prevaleça sobre o primeiro. Medidas compensatórias devem ser tomadas nesses casos para a redução do impacto ambiental (Art. 6(4)(1) da Diretiva 1992/43/CEE). Referido dispositivo prescreve que:

${ }^{18}$ M. Herberg, 'Global Legal Pluralism and Interlegality: Environmental Self-Regulation in Multinational Enterprises as Global Law-Making' in: O. Dilling, M. Herberg, G. Winter, Responsible Business... (cit. nota 15), p. 30-32. 
Se, apesar de a avaliação das incidências sobre o sítio ter levado a conclusões negativas e na falta de soluções alternativas, for necessário realizar um plano ou projecto por outras razões imperativas de reconhecido interesse público, incluindo as de natureza social ou económica, o Estado-membro tomará todas as medidas compensatórias necessárias para assegurar a protecção da coerência global da rede Natura 2000. [...]

Outro exemplo igualmente sofisticado encontra-se na Lei Federal Alemã de Proteção da Natureza (Bundesnaturschutzgesetz - BNatSchG) ${ }^{19}$. O parágrafo 15 da $B N a t S c h G$ estabelece que, se um projeto causar alterações significativa na natureza e na paisagem (Eingriff in Natur und Landschaft), os seguintes critérios devem ser atendidos: primeiramente, deve-se avaliar se os efeitos adversos do projeto podem ser evitados. Aqui, buscamse variantes do projeto que interfiram menos na natureza ${ }^{20}$. Como segundo passo, os efeitos adversos tidos como inevitáveis devem ser compensados, seja por meio de medidas compensatórias qualitativamente equivalentes e próximas ao local (Ausgleichsmaßnahme), seja por meio de medidas compensatórias em local possivelmente mais distante (Ersatzmaßnahme). Em um terceiro passo, o dano remanescente deve ser sopesado com a importância do projeto: se o dano for maior que a importância do projeto, este não é permitido. Diversamente, se for menor, alguma compensação monetária deve ser paga.

Seguem abaixo, de forma sintetizada, outros exemplos do Princípio da Ecoproporcionalidade. Um breve comentário em chaves indica quais elementos da ecoproporcionalidade estão presentes:

1- Uma derrogação das obrigações de proteção de espécies de pássaros ameaçados é permissível por razões de interesse público de saúde e segurança, segurança aérea e prevenção de sérios danos a plantações "sempre que não exista outra solução satisfatória" (Art. 9 Diretiva 2009/147/CE)) [objetivo a ser justificado, alternativas a serem testadas];

2- Estados membros podem derrogar da obrigação de garantir uma boa qualidade da água se as necessidades ambientais e socioeconômicas satisfeitas pelo uso da água não puderem ser satisfeitas por outros meios que constituam uma opção ambiental significativamente melhor que

\footnotetext{
${ }^{19}$ Parágrafo 15 da Lei Federal de Proteção da Natureza (Bundesnaturschutzgesetz -BNatSchG).

${ }^{20}$ Nesse estágio, contudo, o projeto não pode ser colocado em questão in toto e o escopo das alternativas limita-se àquelas situadas na mesma localidade.
} 
não acarrete custos desproporcionais. (Art. 4(5) Diretiva 2000/60/CE) [alternativas a serem testadas, objetivo a ser considerado];

3- Novos produtos fitofarmacêuticos que contenham determinadas substâncias intrinsecamente perigosas podem não ser aprovados se, para o uso pretendido, já exista um outro produto autorizado ou um método não químico de controle ou prevenção que seja mais seguro para o ambiente (Art. 50(1)(a) Regulamento (CE) 1107/09) [alternativas a serem testadas];

4- A produção e comercialização de certos produtos químicos intrinsecamente perigosos somente podem ser autorizadas se o risco para a saúde ou o ambiente for devidamente superado pelos benefícios socioeconômicos e se não existirem substâncias ou tecnologias alternativas adequadas (veja Art. 60 (2) Regulamento (CE) 1907/06) [alternativas a serem testadas, solução a ser sopesada com o objetivo];

5- Uma avaliação de impacto ambiental deve mostrar quais alternativas ao projeto foram testadas e o porquê de terem sido rejeitadas (Art.5(3) Diretiva 85/337/CEE, consoante nova redação; Art.5 Diretiva 2001/42/CE) [alternativas a serem testadas];

6- Um operador de uma instalação perigosa deve empregar as melhores técnicas disponíveis, definidas como técnicas de proteção ambiental que são as mais eficientes, avançadas e apropriadas em termos práticos, mas também economicamente viáveis e que considerem os custos e as vantagens (Art. 2 número 10 Diretiva 2010/75/UE) [alternativas a serem testadas, custos a serem sopesados com as vantagens ambientais].

Inúmeros acordos internacionais também adotam elementos do Princípio da Ecoproporcionalidade:

De acordo com a Convenção de Estocolmo sobre Poluentes Orgânicos Persistentes (POPs):

[...] ao avaliar propostas para construção de novas instalações ou modificações significativas em instalações existentes que utilizam processos que liberam as substâncias químicas relacionadas neste Anexo, deve ser dada atenção prioritária aos processos, técnicas ou práticas alternativas que tenham aplicação semelhante mas que evitem a formação e liberação de tais substâncias químicas (Anexo A, Parte V, B, (b)) [alternativas a serem testadas].

A Convenção sobre Avaliação dos Impactos Ambientais num Contexto Transfronteiras prevê que a avaliação de impacto ambiental 
contenha uma "descrição, se for caso disso, das soluções alternativas (por exemplo, no que diz respeito ao local de implantação ou à tecnologia) que podem ser razoavelmente consideradas sem omitir a opção 'zero' (ausência de intervenção) ${ }^{21}$ " [alternativas a serem testadas].

Consoante com o Protocolo relativo à Avaliação Ambiental Estratégica, o relatório ambiental "identificará, descreverá e avaliará os prováveis efeitos significativos da aplicação do plano ou programa no ambiente, e na saúde, e as soluções alternativas razoáveis ${ }^{22}$ " [alternativas a serem testadas].

A Convenção de Viena para Proteção da Camada de Ozônio sugere um intercâmbio, entre as partes contratantes, de informação técnica sobre (i) "a disponibilidade e os custos de substitutos químicos e de tecnologias alternativas para reduzir as emissões de substâncias modificadoras do ozônio e pesquisas, planejadas ou em curso, referentes ao assunto"; "limitações e riscos envolvidos no uso de substitutos químicos ou de outra natureza", assim como de informações socioeconômicas e comerciais sobre as substâncias referidas no anexo I, que incluem informações, entre outras, sobre "os custos, riscos e benefícios das atividades humanas que possam diretamente modificar a camada de ozônio, e dos impactos de medidas regulamentadoras tomadas, ou que possam vir a ser tomadas, para controlar tais atividades ${ }^{23}$ " [alternativas a serem testadas, objetivo ("benefícios") a ser considerado].

Por isso, vê-se que a ecoproporcionalidade vem sendo adotada por um número de atos legais nacionais, da União Europeia e internacionais em diferentes formas, algumas vezes em uma versão bastante compreensiva. Parece existir uma ratio por trás da configuração da ecoproporcionalidade enquanto princípio: o teste da ecoproporcionalidade parece ser tanto mais exigente quanto mais valioso for o recurso natural em apreço ou mais grave for o efeito ambiental adverso.

Nesse sentido, a versão particularmente estrita para a rede Natura 2000 justifica-se pela raridade dos recursos protegidos. Em contraste, a versão branda requerida para uma avaliação de impacto ambiental (AIA) pode derivar do fato de uma mesma AIA cobrir muitos efeitos e o ambiente

\footnotetext{
${ }^{21}$ Convenção de Espoo, na Finlândia, sobre Avaliação dos Impactos Ambientais num Contexto Transfronteiras, de 1991, Art. 4 c/c Apêndice II (b).

${ }^{22}$ Protocolo relativo à Avaliação Ambiental Estratégica à Convenção sobre Avaliação dos Impactos Ambientais num Contexto Transfronteiras, de 2003, Art. 7 (2).

${ }^{23}$ Convenção de Viena para Proteção da Camada de Ozônio de 1985, Anexo II, números 4 e 5.
} 
como um todo, e não apenas alguns efeitos sérios ou recursos ameaçados em particular.

\subsection{Normas sociais e legais combinadas}

Por vezes a lei não é conclusiva para regular um problema. Nesses casos, o Princípio da Ecoproporcionalidade, enquanto norma social complementar à jurídica, pode ser um guia para os atores. Destacam-se, a seguir, três situações ilustrativas de como essa função complementar é a mais promissora: quando as normas legais são completamente inexistentes, estruturalmente nada ambiciosas ou muito vagas.

\subsection{1 Áreas não regulamentadas}

Empresas multinacionais frequentemente investem em países onde não existem padrões ambientais adequados. De acordo com o Direito Internacional Consuetudinário, as leis domésticas das nações em que essas empresas se encontram não são aplicáveis em um país estrangeiro ${ }^{24}$. Como já indicado, porém, essas empresas não exploram a existência de uma lacuna regulatória, mas se esforçam para algum tipo de autorregulamentação. Se elas vão além do que o direito em vigor exige, isso é frequentemente motivado pelo cálculo econômico, a exemplo da imagem de seus produtos nos países consumidores ou de economias de escala para tecnologias de abatimento de poluição. Entretanto, a ambição poderia ser baseada também no respeito pela natureza e um senso de necessidade de justificar a sua utilização. A ecoproporcionalidade enquanto norma social seria um princípio aplicável nesta situação, pelo menos na forma de alternativas a serem testadas. As diretrizes do OCDE já foram citadas como exemplo que poderia ser mais elaborado.

\subsubsection{Solapando padrões}

Geralmente, padrões ambientais que definem objetivos qualitativos para ar, água, solo, biodiversidade etc. baseiam-se em um conhecimento insuficiente a respeito do nível apropriado de proteção. Como um dispositivo de segurança, alguns diplomas normativos, tais como os rela-

${ }^{24}$ P. Birnie, A. Boyle, C. Redgwell, International law and the environment, 3.ed., Oxford, Oxford University Press, 2009, p. 788. 
tivos a instalações perigosas, requerem a aplicação das melhores técnicas disponíveis mesmo se o padrão ambiental não for excedido. Mas em outras áreas essa exigência não se aplica. No conceito de comércio de emissões do direito sobre proteção do clima, ela foi até mesmo rejeitada. Embora o estabelecimento de tetos (capping) de emissões no sistema do Protocolo de Kyoto tenha obviamente sido muito leniente, os emissores não são obrigados a fazer o uso da melhor técnica para redução de poluentes, mas têm permissão e são até mesmo estimulados a vender licenças não utilizadas derivadas de uma cota fixa ${ }^{25}$. A ecoproporcionalidade apresentaria uma base para ir além, no respeito à natureza.

A ecoproporcionalidade poderia também servir de fundamento para o Princípio da Precaução. Enquanto o Princípio da Precaução é construído para significar que a maioria dos limites ambientais baseia-se em conhecimentos incertos, o fato é que a fixação de limites é uma luta política entre interesses econômicos e ecológicos que frequentemente desconsidera o conhecimento científico. Precaução é, portanto, uma posição contingente daqueles que perderam o jogo. Apoiá-lo numa presunção a favor da natureza ao menos reconheceria que precaução é uma questão política antes que de cognição. A exigência de que a melhor tecnologia disponível deve ser aplicada é, então, uma medida não para lidar com a incerteza, mas para prestar homenagem à crescente escassez de recursos naturais, a sugerir que os recursos naturais não deveriam ser consumidos se o consumo puder ser evitado.

\subsubsection{Referências pela lei formal}

Algumas vezes a lei explicitamente se refere a normas sociais. Isso é verdade, por exemplo, para os padrões de devida diligência (cautela) na responsabilidade civil, deveres de cuidado em direito ambiental, boas práticas em direito de agricultura etc. Em tais casos, o Princípio da Ecoproporcionalidade pode servir como guia para a adoção de regras mais elaboradas.

Frequentemente a lei não se refere explicitamente a normas sociais, mas confia implicitamente nelas porque o problema em jogo foge a uma regulamentação precisa. Por exemplo, recursos naturais vivos como

\footnotetext{
${ }^{25}$ A respeito dessa observação cf., em maior detalhe, G. Winter, The climate is no commodity: Taking Stock of the Emissions Trading System, Journal of Environmental Law 22:2 (2010), p. 1-25, sobretudo p. 16.
} 
plantas, animais e seus ecossistemas possuem a capacidade de reprodução e recuperação de um dano. A capacidade é limitada, pois muitas espécies perdidas não podem ser recuperadas, habitats destruídos recuperam-se lentamente, substâncias tóxicas podem persistir por milhares de anos e assentamentos humanos dificilmente podem ser removidos. Mas, antes de se atingir essas situações limites, existe espaço para moldar a natureza e, assim, uma necessidade de gerenciamento.

Nesse contexto, padrões de proteção são frequentemente formulados em termos amplos. Por exemplo, quando redes de transporte e energia são construídas elas ocorrem inevitavelmente à custa da natureza viva. Como poderia ser determinado se deve haver tolerância ou não? Mais uma vez, a ecoproporcionalidade ajudaria aqui como moldura para o sopesamento de interesses, mesmo que não tenha sido introduzida como um padrão jurídico.

\section{SOBREPONDO PROPORCIONALIDADE NO DIREITO AMBIENTAL}

A ecoproporcionalidade e a socioproporcionalidade parecem estar se sobrepondo na esfera do Direito Ambiental. Nesse ramo jurídico,

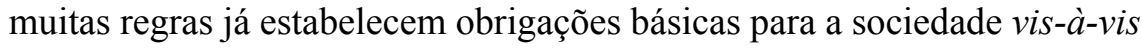
a natureza, exigindo a proteção desta e, obviamente, também a proporcionalidade de meios e fins, incluindo o teste de alternativas. Por exemplo, a Lei Federal Alemã para Proteção de Imissões (Bundesimmissionsschutzgesetz - BImSchG) autoriza a autoridade competente a ordenar que o operador de uma instalação perigosa melhore sua performance ambiental, a não ser que isso cause custos desproporcionais. O Artigo 17 do referido diploma dispõe que:

(1) Para o cumprimento das obrigações advindas desta Lei ou de qualquer decreto que a regulamente, poderão ser realizadas exigências mesmo após a emissão da licença [ambiental] ou após a notificação de alterações consoante o §15 I. Se, depois da emissão da licença ou da notificação de alterações consoante o $§ 15$ I, a proteção da coletividade ou da vizinhança contra efeitos ambientais deletérios ou outros perigos, desvantagens significativas ou perturbações consideráveis mostrar-se inadequada, a autoridade [ambiental] competente pode emitir exigências subsequentes.

(2) A autoridade competente não deverá fazer uma exigência subsequente se esta 
for desproporcional, sobretudo se o esforço necessário para o cumprimento da exigência inicial não for proporcional com o efeito desejado; nesse sentido, atenção especial deve ser prestada à natureza, ao volume e à periculosidade das emissões originadas de uma instalação e das imissões por ela lançadas, bem como à vida útil e às características técnicas da instalação. (grifou-se)

A proporcionalidade é, nesse sentido, também um princípio importante em Direito Internacional. Por exemplo, o Artigo 2.2 do Acordo sobre Barreiras Técnicas ao Comércio exige que uma medida visando a um interesse público, como a saúde ou a proteção ambiental, não deverá ser mais restritiva que o necessário. O Órgão de Apelação estabeleceu uma metodologia sofisticada de como aplicar o teste, a qual requer seja considerado: (i) o grau em que a medida contribui para o objetivo legítimo em questão; (ii) a restrição da medida ao comércio; e (iii) a natureza dos riscos em questão e a gravidade das consequências que poderiam surgir do não alcance do(s) objetivo(s) perseguido(s) pelo Estado-Membro com a medida. Na maioria dos casos, a comparação da medida desafiada e as medidas alternativas possíveis deve ser realizada. Mais particularmente, pode ser relevante para o propósito da comparação considerar se a alternativa proposta é menos restritiva ao comércio, se ela traria uma contribuição equivalente para o objetivo legítimo relevante considerando os riscos que o não alcance dele acarretaria, e se é razoavelmente disponível ${ }^{26}$.

Porém, esse tipo de proporcionalidade, conquanto lide com a proteção ambiental, é ainda caracterizado pela lógica de minimização de intrusões em interesses sociais, como só acontece na sua aplicação nas relações Estado-cidadão.

A proteção ambiental aparece, aqui, como um interesse público. Os meios para alcançá-lo devem ser limitados a fim de proteger direitos individuais. Em contraposição, a ecoproporcionalidade poderia reverter a questão e demandar que os interesses sociais sejam limitados tendo em vista a proteção da natureza.

A socioproporcionalidade, mesmo no campo das políticas de proteção ambiental, começa como uma presunção a favor dos interesses sociais, enquanto a ecoproporcionalidade parte da presunção em prol da proteção da natureza. Na primeira visão, a humanidade aparece como senhora e a natureza como serva; na segunda, a natureza é vista como o

${ }^{26}$ AB Tuna WT/DS381/AB/R, No. 322. 
recurso sem o qual a humanidade não consegue sobreviver.

A distinção entre socioproporcionalidade no âmbito da política ambiental e ecoproporcionalidade pode parecer acadêmica, vez que em ambos os conceitos interesses sociais são ponderados com interesses da natureza. Mas como a lei aplicável é frequentemente indeterminada, pontos básicos de partida e orientações fazem a diferença. Por exemplo, um importante traço distintivo da ecoproporcionalidade é que ela coloca interesses de bem-estar individual e social em questão de modo mais radical que a socioproporcionalidade.

Ao revés, no Direito Ambiental tradicional, esses interesses permanecem largamente inquestionáveis. Por exemplo, no já citado Artigo 17 da BImSchG, somente a vida útil e as características das instalações são consideradas do lado do interesse social, o mesmo ocorrendo com o Art. 2.2 do Acordo sobre Barreiras Técnicas ao Comércio ao considerar apenas o comércio internacional livre. Não se questiona se a instalação e o comércio internacional, respectivamente, prestam serviços à sociedade. Em contraste, a ecoproporcionalidade exigiria mais fundamentadamente uma reflexão sobre objetivos e a justificação deles.

Tabela 1 é uma tentativa de estruturar a diferença entre as duas proporcionalidades segundo uma variação das respostas aos quatro testes.

\begin{tabular}{|l|l|l|}
\hline & Socioproporcionalidade & Ecoproporcionalidade \\
\hline $\begin{array}{l}\text { Objetivo } \\
\text { justificável? }\end{array}$ & $\begin{array}{l}\text { Justificar a proteção } \\
\text { da natureza }\end{array}$ & $\begin{array}{l}\text { Justificar benefícios } \\
\text { sociais }\end{array}$ \\
\hline $\begin{array}{l}\text { Meios } \\
\text { adequados? }\end{array}$ & $\begin{array}{l}\text { Excluir opções que acarretem } \\
\text { um ônus supérfluo para a so- } \\
\text { ciedade }\end{array}$ & $\begin{array}{l}\text { Excluir opções que acar- } \\
\text { retem um ônus supérfluo } \\
\text { para a natureza }\end{array}$ \\
\hline $\begin{array}{l}\text { Meios necessá- } \\
\text { rios? }\end{array}$ & $\begin{array}{l}\text { Escolher a opção que acarrete } \\
\text { o menor ônus para a socieda- } \\
\text { de, sendo ao mesmo tempo } \\
\text { adequada }\end{array}$ & $\begin{array}{l}\text { Escolher a opção que acar- } \\
\text { rete o menor ônus para a } \\
\text { natureza, sendo ao mesmo } \\
\text { tempo adequada }\end{array}$ \\
\hline $\begin{array}{l}\text { Meios } \\
\text { cionais (sopesa- } \\
\text { dos)? }\end{array}$ & $\begin{array}{l}\text { Sacrificar a natureza se o ônus } \\
\text { para a sociedade for excessi- } \\
\text { vo }\end{array}$ & $\begin{array}{l}\text { Sacrificar o benefício social } \\
\text { se ônus para a natureza } \\
\text { for excessivo }\end{array}$ \\
\hline
\end{tabular}

Tabela 1: Comparação das duas proporcionalidades 
Apesar das diferenças, parece sensato, quando objetivos sociais e ecológicos conflitarem entre si, integrar ambas as proporcionalidades - social e ecológica - em um modelo abrangente de sopesamento e levar em conta a importância dos respectivos bens jurídicos envolvidos mediante uma ponderação adequada ${ }^{27}$. Uma ponderação justa somente tem êxito, contudo, se não se parte da socioproporcionalidade de antemão e se considera igualmente a perspectiva da ecoproporcionalidade. Isso leva a um maior questionamento dos objetivos sociais e a uma busca mais séria por soluções compatíveis com a natureza.

\section{CONCLUSÃO}

O impacto da humanidade sobre os recursos e ciclos naturais tornou-se um fenômeno dominante do estado da Terra. Alguns veem uma nova era emergindo: a do antropoceno. O impacto, porém, não é acompanhado de capacidade suficiente de governança humana que possa assegurar um estado de natureza apto à sobrevivência da humanidade.

Por algum tempo, a governança humana vem tentando encontrar e garantir os limites de exploração tolerados pela natureza. Em geral, sob a égide do "direito de proteção ambiental" tem-se aplicado uma abordagem de tentativa e erro, até mesmo onde o Princípio da Precaução seja propagado.

Isso demonstra que os seres humanos têm esperado a natureza provar - muitas vezes de maneira irreversível - que tais limites foram violados. A preocupação com as respostas da natureza tem cegado os olhos humanos para o fato de que o problema não é a natureza, mas a humanidade. Não são as necessidades da natureza que devem ser colocadas em questão, mas as aspirações humanas e as estruturas socioeconômicas que as promovem. Estes são fatores determinantes e conducentes a um antropoceno descontrolado.

Esses fatores precisam ser (auto)regulados. A ecopropocionalidade é uma ferramenta para tanto. Ao exigir a exposição de razões para os objetivos humanos e seus meios, a ecoproporcionalidade, tanto como uma

\footnotetext{
${ }^{27}$ Para maiores considerações, cf. Gerd Winter, O princípio da análise de alternativas: uma perspectiva europeia, in: C. M. Manzolli Palma; F. S. Neto; T. C. Silbellini de Oliveira (eds.), Direito ambiental: efetividade e outros desafios. Estudos em homenagem a Paulo Affonso Leme Machado, São Paulo, Lex Magister, 2012, 9-23.
} 
norma social quanto como uma norma jurídica gradualmente emergente, contribui para um novo paradigma de regras que disciplinam a interação homem-natureza.

\section{REFERÊNCIAS}

Birnie, P., Boyle, A., Redgwell, C., International law and the environment, 3.ed., Oxford, Oxford University Press, 2009.

Dilling, O., Proactive compliance? Repercussions of national regulation in standards of transnational business networks, in Dilling, O.; Herberg, M.; Winter, G. (eds.), Responsible business. Self-governance and law in transnational economic transactions, Oxford, Hart Publishing, 2008.

Dupuis, G. ; Guédon, M.-J. ; Crétien, P., Droit administratif, 12.ed., Paris, Dalloz, 2011.

Field, B. C., Field, K. C., Environmental economics, 5. ed., Boston, McGraw-Hill, 2009.

Götz, V., Allgemeines Polizei- und Ordnungsrecht, 11.ed., Göttingen, Vandenhoeck\&Ruprecht, 1993.

Harlow, C., Rawlings, R., Law and administration, Cambridge, Cambridge University Press, 1997 (reimpressão de 2006).

Herberg, M., Global legal pluralism and interlegality: environmental selfregulation in multinational enterprises as global law-making, in Dilling, O., Herberg, M., Winter, G. (eds.), Responsible business self-governance and law in transnational economic transactions, Oxford, Hart Publishing, 2008, 17-40.

Lerche, P., Übermaß und Verfassungsrecht. Zur Bindung des Gesetzgebers an die Grundsätze der Verhältnismäßigkeit und Erforderlichkeit, Köln, Carl Heymanns, 1961.

Machado, Paulo Affonso Leme, Direito ambiental brasileiro, 21. ed., São Paulo, Malheiros, 2013.

Schepel, H., The constitution of private governance product standards of integrating markets, Oxford, Hart Publishing, 2005. 
Serre, M., Contract naturel, Paris, Flammarion, 1992.

Stone, Chr. D., Should trees have standing? Law, morality, and the environment, 3.ed, Oxford, Oxford University Press, 2010.

Sumner, W.G., Folkways. A study of the sociological importance of usages, manners, customs, mores and morals, Boston, Ginn and Company, 1906.

Wade, H. W. R., Administrative law, 5. ed., Oxford, Clarendon Press, 1982.

Weber, Max, Rechtssoziologie ed. J. Winckelmann, Neuwied, Luchterhand, 1960.

Winter, Gerd, C. M. Manzolli Palma, F. S. Neto, T. C. Silbellini de Oliveira (eds.), Direito ambiental: efetividade e outros desafios. Estudos em homenagem a Paulo Affonso Leme Machado, São Paulo, Lex Magister, 2012.

, The climate is no commodity: Taking stock of the emissions trading system, Journal of Environmental Law 22:2 (2010).

Recebido: 27/01/2014

Aceite: $22 / 02 / 2014$ 